\title{
Perinatal factors influencing the neonatal hearing screening results
}

\author{
Mahbod Kaveh', Seyedeh Nastaran Mirjalali ${ }^{2}$, Mamak Shariat ${ }^{3}$ and Mohammad Reza Zarkesh ${ }^{4,5^{*}}$ (D)
}

\begin{abstract}
Background: Previous studies have indicated that the majority of cases with "failed" results related to transient evoked otoacoustic emissions (OAE) test have the normal hearing. The present study aimed to assess the possible relationships between perinatal factors and the false-positive OAE results.

Methods: A case-control study was carried out in an Iranian Hospital in 2020. Based on the OAE results on the first day of life, newborns were divided into 2 groups; Control group included subjects with "Pass" OAE results. Every neonate with "Fail" OAE result was referred for auditory brainstem response (ABR). Neonates with bilateral fail OAE but normal ABR results (false-positive OAE) were considered as the case group. All recorded data were analyzed to assess the possible correlations between maternal/neonatal factors and the false-positive OAE results.
\end{abstract}

Results: One hundred and eighty-one neonates entered the study. Of all included neonates, 87 (48.1\%) cases showed bilateral fail OAE and 94 (51.9\%) subjects passed the OAE test. Normal ABR results (false-positive OAE) were observed in all cases with bilateral fail OAE. Comparisons of variables affecting the OAE results showed that of all perinatal factors, neonate's sex $(p=0.046)$ and cesarean section $(p=0.003)$ were the only influencing factors that increased the risk of false-positive OAE results.

Conclusion: Based on the results, the cesarean section delivery and neonate's male sex increased the risk of falsepositive results related to OAE test. Implementing other screening tests such as ABR or Automated ABR as the initial screening test could be suggested for such cases.

Keywords: Transient evoked otoacoustic emissions, Auditory brainstem response, False positive, Neonate

\section{Background}

Hearing loss is one of the most frequent congenital anomalies in the neonates. It has been reported that one in every 1000 newborns suffers from congenital bilateral hearing loss $[1,2]$. Infants with undetected hearing loss often face significant complications related to emotional, intellectual, linguistic, speech, and social delays [3, 4].

To decrease the impact of adverse effects associated with congenital hearing loss on the infant's life, early

\footnotetext{
* Correspondence: zarkesh@tums.ac.ir

${ }^{4}$ Maternal, Fetal and Neonatal Research Center, Tehran University of Medical Sciences, Tehran, Iran

${ }^{5}$ Department of Neonatology, Yas Women Hospital, Tehran University of Medical Science, Sarv Ave., North Nejatolahi Street, Tehran 1598718311, Iran Full list of author information is available at the end of the article
}

diagnosis and preventive interventions have been recommended [4]. There are different screening methods to evaluate hearing status, as soon as possible, in newborns. Recently transient evoked otoacoustic emissions (TEOAE) and auditory brain stem response (ABR) with high sensitivity and specificity are widely used as universal newborn hearing screening (UNHS) tests. However false-positive results may cause some misinterpretations and parental anxiety $[4,5]$. Previous studies indicated that the majority of cases with "failed" results related to screening tests have the normal hearing sense. A high rate of false-positive result ranged from 2.5 to $8 \%$ was reported regarding to use of universal newborn hearing screening tests including OAE. The results of the studies have also demonstrated that some factors including ear

(c) The Author(s). 2021 Open Access This article is licensed under a Creative Commons Attribution 4.0 International License which permits use, sharing, adaptation, distribution and reproduction in any medium or format, as long as you give appropriate credit to the original author(s) and the source, provide a link to the Creative Commons licence, and indicate if changes were made. The images or other third party material in this article are included in the article's Creative Commons licence, unless indicated otherwise in a credit line to the material. If material is not included in the article's Creative Commons licence and your intended use is not permitted by statutory regulation or exceeds the permitted use, you will need to obtain permission directly from the copyright holder. To view a copy of this licence, visit http://creativecommons.org/licenses/by/4.0/ The Creative Commons Public Domain Dedication waiver (http://creativecommons.org/publicdomain/zero/1.0/) applies to the data made available in this article, unless otherwise stated in a credit line to the data. 
canal debris, ambient sound, myogenic interference, infant's position, or activity may falsely influence the results of the screening tests $[5,6]$. An investigation demonstrated that of 1000 screened newborns using TEOAE, 18 subjects had impaired two-step OAE results (OAE implementing on first and 10 to 15 days after neonate's birth). ABR results showed that of these subjects, $12(1.2 \%)$ responses had been false positive [4].

Several studies have evaluated the possible associations between maternal/neonatal factors and false-positive neonatal hearing screening tests; Schwarz et al. showed that 70 newborns who failed OAE, could pass the subsequent ABR. they highlighted that of different maternal/ neonatal factors including mother's health status, age, gravida, parity, amniotic fluid index (AFI), mode of delivery, tobacco \& smoking, illegal drug use, alcohol consumption, gestational age, neonate's gender, head circumference, birth weight, height, and Apgar scores, only smoking and drug use could falsely affect the results [7]. The other study demonstrated that regardless of the mode of delivery, false-positive rates related to the first (81.9\%) and second (14.5\%) OAE screening test were high among neonates [8]. Kepekci et al. have demonstrated a higher false-positive rate in the first OAE among newborns born by cesarean section $(\mathrm{C} / \mathrm{S})$ compared to those born by normal vaginal delivery [9].

False-positive results of hearing screening tests may interfere and postpone the accurate census associated with neonatal hearing loss or impairment. Moreover, requiring repeated screening tests may impose heavy costs on the health system and the family economy. Finally, a falsepositive hearing screen may impact some negative psychological and emotional stress on neonates' parents. Therefore, the present study was carried out to assess the possible relationships between several perinatal factors and false-positive results of the OAE test. It is supposed that by identifying such involving factors, implementing of another proper hearing screening test as the initial screening test may eliminate these parents' discomforts and mentioned complications.

\section{Methods}

\section{Study design}

A case-control study was carried out in Yas Women Hospital affiliated to Tehran University of Medical Sciences (Tehran-Iran) between January and June 2020. The population study was single birth neonates with gestational age $>34$ weeks who attended for hearing screening test by OAE (Maico Diagnostics Universal Neonatal Hearing Screening; Germany) on the first day of life. Based on the OAE results, newborns were divided into 2 groups. The control group included subjects with "Pass" results when there was OAE response to the stimulus at $>35 \mathrm{~dB}$ Hearing Level (dBHL) [10]. Every neonate with Fail result (no response to the stimulus) was referred for auditory brainstem response (using ABR; The Interacoustics Eclipse; USA) the next day. Neonates with bilateral Fail OAE but normal ABR results (false-positive $\mathrm{OAE}$ ) were considered as the case group. Both automated $\mathrm{OAE}$ and $\mathrm{ABR}$ tests were done by an expert audiologist. The case and control groups were matched regarding to age and sex. Newborns with failed both $\mathrm{OAE}$ and $\mathrm{ABR}$ tests as well as having the risk factors associated with hearing loss (Maternal infections, Hyperbilirubinemia, congenital head and neck abnormalities or syndromes) were also excluded from the study.

Demographic data related to all neonates and their mothers including maternal age, level of education, parity, gravid, type of delivery, prenatal corticosteroid administration, prenatal complications and underlying diseases, amniotic fluid index (AFI), gestational age, the first and fifth minutes Agar scores, anthropometric measures, and history of hospitalization were extracted from medical records and recorded.

All recorded data related to the results of hearing screening tests as well as maternal/ neonatal data were analyzed to assess the possible correlations between some maternal-neonatal factors and false positive OAE result.

\section{Ethical considerations}

Ethics approval was obtained from the institutional review board of Tehran University of Medical Sciences according to Helsinki declaration (IR.TUMS.VCR.REC.1398.061). All participants' parents gave written consent before enrollment. Participants' data were considered confidential and no extra cost was imposed on our participants.

\section{Sample size}

Schwarz et al. [7] in a study (determining the affecting factors on false positive OAE test) showed $10 \%$ of false positive OAE in newborns were associated with maternal variables like drug usage, while this rate among the control group was $1.3 \%$. Based on these parameters, using formula for estimation of a proportion between two independent groups with a power of $80 \%$ and an alpha error of $0.05,94$ subjects in each group (for achieving the effective factor on false positive OAE) were included.

$$
\begin{aligned}
n & =2 \frac{\left(z_{1-\frac{\alpha}{2}}+z_{1-\beta}\right)^{2} \overline{p q}}{\left(p_{1}-p_{2}\right)} \\
\alpha & =0.05, \beta=0.2, \mathrm{P}_{1}=0.10, \mathrm{P}_{2}=0.013, \mathrm{Z} 1-\mathrm{a} / 2 \\
& =1.96, \mathrm{Z} 1-\mathrm{B}=0.84, \mathrm{p}=0.055, \mathrm{n}=94
\end{aligned}
$$

\section{Data analysis}

Analyses were statistically performed by using software package SPSS Version 18. Quantitative and qualitative 
variables were reported by mean $\pm \mathrm{SD}$ and percent, respectively. Chi-square, Non-parametric KolmogorovSmirnov test (determining normal or non-normal distribution of variables), and Mann-Whitney test (for comparison of quantitative variables with non-normal

Table 1 All participants' demographical and obstetrical data

\begin{tabular}{|c|c|c|}
\hline Variables & Number & Percent \\
\hline \multicolumn{3}{|l|}{ Level of educations } \\
\hline Lower diploma & 25 & 13.9 \\
\hline Diploma & 94 & 52.2 \\
\hline Higher diploma & 61 & 33.8 \\
\hline \multicolumn{3}{|l|}{ Maternal health status } \\
\hline Healthy & 118 & 65.2 \\
\hline None healthy & 63 & 34.8 \\
\hline \multicolumn{3}{|c|}{ Underlying disease in none healthy group } \\
\hline High blood pressure & 4 & 2.2 \\
\hline Urinary tract Infection & 1 & 0.6 \\
\hline Diabetes & 18 & 9.9 \\
\hline Thyroid & 33 & 18.2 \\
\hline other & 7 & 3.9 \\
\hline \multicolumn{3}{|c|}{ Corticosteroid administration } \\
\hline Yes & 20 & 11.0 \\
\hline No & 161 & 89.0 \\
\hline \multicolumn{3}{|l|}{ Occupation } \\
\hline Employed & 13 & 7.2 \\
\hline Unemployed & 168 & 92.8 \\
\hline \multicolumn{3}{|l|}{ Mode of delivery } \\
\hline Cesarean section & 106 & 59.6 \\
\hline Vaginal delivery & 72 & 40.4 \\
\hline \multicolumn{3}{|l|}{ Neonate's sex } \\
\hline Male & 99 & 56.9 \\
\hline Female & 75 & 43.1 \\
\hline \multicolumn{3}{|l|}{ Amniotic fluid status } \\
\hline Oligohydramnios & 1 & 0.6 \\
\hline Polyhydramnios & 1 & 0.6 \\
\hline Normal & 175 & 98.9 \\
\hline \multicolumn{3}{|l|}{ Apgar scores } \\
\hline First minute & $8.9945 \pm .07433$ & \\
\hline Fifth minute & $9.9945 \pm .07433$ & \\
\hline \multicolumn{3}{|l|}{ OAE } \\
\hline Left Pass & 93 & 51.7 \\
\hline Right Pass & 93 & 51.7 \\
\hline Both fail & 87 & 48.1 \\
\hline Both pass & 94 & 51.9 \\
\hline Left fail & 87 & 48.3 \\
\hline Right fail & 87 & 48.3 \\
\hline
\end{tabular}

distribution) were used for determining associations between different maternal/ neonatal factors and false positive OAE test. Binary logistic regression test was also used to eliminate the effects of confounding factors. The level of significance was considered as $P<0.05$.

\section{Results}

One hundred and eighty-one neonates entered the study. None of mothers had smoking, alcohol or drug consumption. The mean of mothers' age, gravid, parity and amniotic fluid index were $30.1508 \pm 5.24401$ years, $1.966 \pm$ $0.8975,1.740 \pm 0.7152$ and $13.271 \pm 3.252$ (Min: 1.195, Max: 25) $\mathrm{Cm}$. The Minimum, Maximum and the mean of neonates' gestational age were $34,40^{+6}$ and $38.423 \pm$

Table 2 Comparison of qualitative variables between the case and control groups

\begin{tabular}{llll}
\hline & Case $\boldsymbol{n}=\mathbf{8 7}$ & Control $\boldsymbol{n}=\mathbf{9 4}$ & $\boldsymbol{P}$ value* \\
\hline $\begin{array}{llll}\text { Level of educations } \\
\text { Lower diploma }\end{array}$ & $12(14)$ & $13(13.8)$ & 0.956 \\
Diploma & $44(51.2)$ & $50(53.2)$ & \\
Higher diploma & $30(34.9)$ & $31(33)$ &
\end{tabular}

None healthy group with underlying disease

\begin{tabular}{|c|c|c|c|}
\hline High blood pressure & $4(4.6)$ & $0(0)$ & 0.116 \\
\hline Urinary tract & $1(1.1)$ & $0(0)$ & \\
\hline Diabetes & $6(6.9)$ & $12(12.8)$ & \\
\hline Thyroid & $14(16.1)$ & $19(20.2)$ & \\
\hline other & $2(2.3)$ & $5(5.3)$ & \\
\hline Healthy group & $60(69.0)$ & $58(61.7)$ & \\
\hline \multicolumn{4}{|c|}{ Corticosteroid administration } \\
\hline Yes & $6(6.9)$ & $14(14.9)$ & 0.101 \\
\hline No & $81(93.1)$ & $80(85.1)$ & \\
\hline \multicolumn{4}{|l|}{ cccupation } \\
\hline Employed & $7(8.0)$ & $6(6.4)$ & 0.776 \\
\hline Unemployed & $80(92.0)$ & $88(93.6)$ & \\
\hline \multicolumn{4}{|l|}{ ype of delivery } \\
\hline Cesarean section & $62(71.3)$ & $44(48.4)$ & 0.002 \\
\hline Vaginal delivery & $25(28.7)$ & $47(51.6)$ & \\
\hline \multicolumn{4}{|l|}{ Jeonate's sex } \\
\hline Male & $57(67.1)$ & $42(47.2)$ & 0.009 \\
\hline Female & $28(32.9)$ & $47(52.8)$ & \\
\hline \multicolumn{4}{|l|}{ Maternal health status } \\
\hline Healthy & $60(69.0)$ & $58(61)$. & 0.305 \\
\hline None healthy & $27(31.0)$ & $36(38.3)$ & \\
\hline \multicolumn{4}{|l|}{ Imniotic fluid status } \\
\hline Oligohydramnios & $1(1.2)$ & $0(0.0)$ & 0.326 \\
\hline Polyhydramnios & $1(1.2)$ & $0(0.0)$ & \\
\hline Normal & $82(97.6)$ & $93(100)$ & \\
\hline
\end{tabular}

${ }^{*}$ Chi-square test 
Table 3 Comparison of quantitative variables between the case and control groups

\begin{tabular}{llll}
\hline & $\begin{array}{l}\text { Case group } \\
\text { Mean } \pm \text { std }\end{array}$ & $\begin{array}{l}\text { Control group } \\
\text { Mean } \pm \text { std }\end{array}$ & $P$ value* \\
\hline Mother's age (Years) & $30.183 \pm 5.386$ & $30.119 \pm 5.135$ & 0.918 \\
Amniotic index (Cm) & $12.935 \pm 3.658$ & $13.109 \pm 2.853$ & 0.337 \\
Gravid & $1.965 \pm 0.881$ & $1.966 \pm 0.917$ & 0.916 \\
Parity & $1.781 \pm 0.722$ & $1.700 \pm 0.710$ & 0.405 \\
Gestational age (Weeks) & $38.289 \pm 1.062$ & $38.538 \pm 1.137$ & 0.074 \\
1st minute Apgar score & $8.988 \pm 0.107$ & $9.000 \pm 0.000$ & 0.299 \\
5th minute Apgar score & $9.9885 \pm 0.107$ & $10.000 \pm 0.000$ & 0.299 \\
Birth weight (g) & $3262.1512 \pm 435.89026$ & $3490.989 \pm 3167.768$ & 0.233 \\
Height $(\mathrm{Cm})$ & $50.6221 \pm 2.19080$ & $50.951 \pm 2.200$ & 0.280 \\
Head $(\mathrm{Cm})$ & $34.8140 \pm 34.8140$ & $34.500 \pm 1.121$ & 0.136 \\
\hline
\end{tabular}

*Mann-Whitney test

1.107 weeks. The mean of neonate's birth weight, Height and head circumference were $3381.655 \pm 2305.851$ ( $\mathrm{min}$; $2270.00 \&$ max; 33,680.00) grams, $50.792 \pm 2.1956$ and $34.653 \pm 1.1633 \mathrm{Cm}$, respectively. Detailed demographical and obstetrical data are shown in Table 1.

\section{Comparison of qualitative and quantitative data between the case and control groups}

Seven cases with Fail OAE results did not attend for ABR. Finally, of all 181 included neonates, 87 (48.1\%) cases showed bilateral Fail OAE and 94 (51.9\%) subjects as the control group passed the OAE test. All 87 cases with bilateral Fail OAE and normal ABR results (falsepositive OAE) were included. As the results are demonstrated in Tables $2 \&$ 3, false-positive OAE results were more common in male cases compared to the females $(p=0.009 ; \mathrm{OR}=2.278,95 \% \mathrm{CI}: 1.232,4.212)$. There was also a significant difference between groups regarding to type of delivery; more neonates in the case group were born by cesarean section ( $p=0.002$; OR $=2.649,95 \% \mathrm{CI}$ : $1.425,4.925)$. No significant differences were observed between groups regarding to maternal occupation $(p=$ $0.776)$, educations $(p=0.956)$, underlying disease $(p=$ $0.116)$, corticosteroid administration $(p=0.101))$. There were also no significant differences between groups with respect to neonatal gestational age $(p=0.074), 1$ st $(p=$ $0.299)$ \& 5th $(p=0.299)$ minutes Apgar scores, birth weight $(p=0.233)$, height $(p=0.280)$ and head circumference $(p=0.136)$.

Adjusting confounding factors, comparison of variables affecting OAE results were also done by logistic regression test (Table 4). The results showed that of all

Table 4 Comparison of maternal/neonatal variables affecting false-positive OAE results (Binary logistic regression)

\begin{tabular}{|c|c|c|c|c|}
\hline Source & Independent Variable & B & $P$ value & $\mathrm{Cl}_{95 \%}$ \\
\hline \multirow[t]{6}{*}{ Neonatal factors } & - Gestational age & 0.206 & 0.203 & $0.895-1.686$ \\
\hline & - 1st minute Apgar & 20.300 & 1.000 & 0.000 \\
\hline & - Sex & 0.681 & 0.046 & $1.011-3.862$ \\
\hline & - Weight & 0.000 & 0.611 & $-0.002-0.000$ \\
\hline & - Height & 0.082 & 0.325 & $0.922-1.279$ \\
\hline & - Head & -0.295 & 0.056 & $0.550-1.007$ \\
\hline \multirow[t]{8}{*}{ Maternal factors } & - Amniotic index & -0.001 & 0.870 & 0.989-1.009 \\
\hline & - Gravid & 0.191 & 0.566 & $0.630-2.329$ \\
\hline & - Parity & -0.441 & 0.310 & $0.274-1.508$ \\
\hline & - Occupation & 0.025 & 0.972 & $0.246-4.270$ \\
\hline & - Type of Delivery & 1.042 & 0.003 & $1.409-5.709$ \\
\hline & - Age & 0.051 & 0.169 & $0.978-1.133$ \\
\hline & - Amniotic fluid index & -0.001 & 0.870 & 0.989-1.009 \\
\hline & - Education & -0.144 & 0.349 & $0.641-1.170$ \\
\hline
\end{tabular}


perinatal factors, neonate's sex $(p=0.046)$ and cesarean section $(p=0.003)$ were the only influencing factors for false-positive OAE results.

\section{Discussion}

In the present study, possible relationships between several perinatal factors and false-positive results related to the OAE test were assessed. By identifying such influencing factors, initially using a more advanced screening test like ABR can eliminate the defect associated with OAE screening test.

Our results showed that of all perinatal factors, neonate's sex was a significant influencing factor on the false-positive OAE test; the majority of the cases were male $(67.1 \%$ vs. $32.9 \%)$. We suppose that this sex-related discrepancy may arise from differences in male and female's skull bones as well as skull structures. A former study has reported that the amplitudes of the otoacoustic emissions for female neonates are greater and more perceptible than their male counterparts [11]. Other studies have also shown that the failed results related to NHS tests were more frequent in male subjects; Lima et al. have reported that $12 \%$ of participants in their study failed the NHS test; of them $55.27 \%$ were male [12]. Other investigation showed that of 88 screened neonates, $39.77 \%$ failed the NHS while the numbers of male subject were significantly higher than females $(62.86 \%$ vs. $51.43 \%)$ [13]. In accordance with our finding da-Silva Reis et al. demonstrated that the fail results associated with the first hearing screening test were significantly frequent among male newborns compared to the females ( $n=34$; male: $28.3 \%$ vs. female: $11.7 \%, p=$ 0.0128). Of all these 34 cases, more male neonates passed the rescreening ABR test than the females (17.6\% vs. $14.7 \%)$ [14].

The results in the current study have also indicated that there was a significant difference between case and control groups regarding to type of delivery; more neonates with false-positive OAE results had been born by cesarean section. The reason may correlate to accumulation of wax or amniotic fluid in the external and middle ear in the cesarean cases. Unlike the OAE test, the ABR test is not affected by such factors [4, 15]. In addition, it is supposed that in the cesarean cases, anesthesia and the time of screening after that may affect the OAE results [16]. According to such findings, we suggest the implementing of ABR test as the first screening test for neonates born by cesarean section. By using this test, rescreenining might be avoided. Compatible to our findings, Xiao et al. have indicated that cesarean section and early screening within the first $42 \mathrm{~h}$ after that have significantly increased the false-positive OAE results among neonates [17]. Smolkin et al. demonstrated that cesarean section could increase the risk of failure of OAE test by
3.2 times compared to vaginal delivery. They have proposed that to decrease the false-positive failure rates among neonates born by cesarean section, OAE screening test should be performed beyond $48 \mathrm{~h}$ after the birth [15]. Oghan et al. reported that of 6044 newborns born by cesarean section, 424 neonates failed the $\mathrm{OAE}$ test while $6.1 \%$ of them could pass the ABR test. Of 4723 subjects with vaginal delivery, 227 neonates failed the OAE test, of them $4.3 \%$ could pass the ABR test. The authors indicated that although false-positive results in the cesarean group were higher than the normal vaginal delivery group; the difference between two groups was not significant [18]. Güven also did not find any significant association between false-positive hearing screening result and the mode of delivery, however the author showed that after fluid resorption in the ear, success rate related to the first OAE was significantly increased [8]. Tabrizi et al. have also noted that for higher success rate, the first OAE test after cesarean delivery should be postponed [19]. In contrast to our finding, Farahani et al. have demonstrate that false-positive OAE results in the vaginal delivery group was significantly higher than the cesarean group (15.5\% vs. 9.5\%) [20].

According to the results, we could not find any significant relationships between false-positive OAE results and other perinatal factors. However further studies with larger sample size, implementing of different screening methods in variable postnatal times may provide more beneficial data.

\section{Conclusion}

In summary based on the results, the cesarean section delivery and neonate's male sex increased the risk of false-positive results related to $\mathrm{OAE}$ test. Implementing other screening tests such as ABR or Automated ABR as the initial screening test could be suggested for such cases. Using these methods as the first screening tool may be cost effective by avoiding of rescreenining and also reduces parents' anxiety related to false-positive results. Moreover, with regard to high rates of falsepositive rates in the implementing of OAE test, the performing the second screening modality for the failed OAE cases should be considered.

\section{Abbreviations}

UNHS: Universal newborn hearing screening; OAE: Otoacoustic emissions; TEOAE: Transient evoked otoacoustic emissions; ABR: Auditory brainstem response; AFI: Amniotic fluid index; C/S: Cesarean section; NVD: Normal vaginal delivery; Dbhl: Decibels Hearing Level

\section{Acknowledgments}

This study was supported by Tehran University of medical sciences (TUMS) and Maternal Fetal and Neonatal Research Center. We acknowledge their kindly supports in this study. 


\section{Authors' contributions}

Dr. MRZ and Dr. MK carried out the design and coordinated the study, participated in most of the experiments. Dr. SNM and Dr. MS coordinated and carried out all the experiments, analysis of data and participated in manuscript preparation. All authors have read and approved the content of the manuscript.

\section{Funding}

This research has been supported by Tehran University of Medical Sciences and health service as well as Maternal Fetal and Neonatal Research Center. This financial support involved providing the screening devices.

\section{Availability of data and materials}

The datasets related our study is available from the corresponding author on reasonable request.

\section{Ethics approval and consent to participate}

Our study was approved by the institutional review board of Tehran University of Medical Sciences and according to Helsinki declaration. All participants' parents of the minors included in this study gave written consent before enrollment. Participants' data were considered confidential and no extra cost was imposed on our participants.

\section{Consent for publication}

Not Applicable.

\section{Competing interests}

The authors declare that there is no conflict of interests.

\section{Author details}

'Department of Pediatrics, Bahrami Hospital, Tehran University of Medical Sciences, Tehran, Iran. ${ }^{2}$ Department of Pediatrics, Faculty of Medicine, Tehran University of Medical Sciences, Tehran, Iran. ${ }^{3}$ Maternal \& Child Health Specialist, Maternal, Fetal and Neonatal Research Center, Tehran University of Medical Sciences, Tehran, Iran. ${ }^{4}$ Maternal, Fetal and Neonatal Research Center, Tehran University of Medical Sciences, Tehran, Iran. ${ }^{5}$ Department of Neonatology, Yas Women Hospital, Tehran University of Medical Science, Sarv Ave., North Nejatolahi Street, Tehran 1598718311, Iran.

Received: 25 July 2020 Accepted: 16 December 2020

Published online: 06 January 2021

\section{References}

1. Valse D, Nagarathna HK. Efficacy of TEOAEs and BERA as screening tools for deafness in newborn. Int J Otorhinolaryngol Head Neck Surg. 2017;3(3):4915.

2. Qi B, Cheng X, En H, Liu B, Peng S, Zhen Y, Cai Z, Huang L, Zhang L, Han D. Assessment of the feasibility and coverage of a modified universal hearing screening protocol for use with newborn babies of migrant workers in Beijing. BMC Pediatr. 2013;13:116.

3. Crouch E, Probst J, Bennett K. Evaluating loss to follow-up in newborn hearing Screeningin a southern state. JEHDI. 2017;2(1):40-7.

4. Yousefi J, Ajalloueyan M, S Amirsalari S, Hassanali Fard M. The specificity and sensitivity of transient Otoacustic emission in neonatal hearing screening compared with diagnostic test of auditory brain stem response in Tehran hospitals. Iran J Pediatr. 2013;23(2):199-204.

5. Poulakis Z, Barker M, Wake M. Six month impact of false positives in an Australian infant hearing screening programme. Arch Dis Child. 2003;88:204

6. Clemens CJ, Sherri A. Davis. Minimizing false-positives in universal newborn hearing screening: a simple solution. Pediatrics. 2001;107(3):1-3.

7. Schwarz Y, Kaufman GN, Daniel SG. Newborn hearing screening failure and maternal factors during pregnancy. Int J Pediatr Otorhinolaryngol. 2017;103: 65-70.

8. Gülseven GS. The effect of mode of delivery on newborn hearing screening results. Turk Arch Otorhinolaryngol. 2019;57(1):19-23.

9. Hamdi Kepekci A, Bestemi KA. Effect of delivery modes on hearing screening results. Glob J Otolaryngol. 2019;20(4):556045.

10. Amini E, Farahani Z, Rafiee Samani M, Hamedi H, Zamani A, Karimi Yazdi A, Nayeri F, Nili F, Rezaeizadeh G. Assessment of hearing loss by OAE in asphyxiated newborns. Iran Red Cres Med J. 2014;16(1):6812.
11. Durante AS, Carvallo RM, da Costa FS, Soares JC. Characteristics of transient evoked otoacoustic emissions in newborn hearing screening program. Pro Fono. 2005;17(02):133-40.

12. Lima MCMP, Rossi TRF, Françozo MFC, Marba ST, Lima GML, Santos MFC. Detection of hearing loss in neonates of a public hospital. Rev Soc Bras Fonoaudiol. 2010;15:1-6.

13. Maia RM, Silva MAM, Tavares PMB. Newborn hearing health: speech therapy acting on family health strategy. Rev CEFAC. 2012;2:206-14.

14. da Silva RF, de Oliveira GC, De Conto J, lantas M, Lüders D, Marques J. Hearing assessment of neonates at risk for hearing loss at a hearing health high complexity service: an electrophysiological assessment. Int Arch Otorhinolaryngol. 2019;23(2):157-64.

15. Smolkin T, Mick O, Dabbah M, Blazer S, Grakovsky G, Gabay N, et al. Birth by cesarean delivery and failure on first otoacoustic emissions hearing test. Pediatrics. 2012:130:95-100.

16. Khoza-Shangase $K$, Joubert $K$. The influence of epidural anesthesia on newborn hearing screening: a pilot study. J Pharm Bioall Sci. 2011;3(1):135-41.

17. Xiao T, Li Y, Xiao L, Jiang L, Hu Q. Association between mode of delivery and failure of neonatal acoustic emission test: a retrospective analysis. Int J Pediatr Otorhinolaryngol. 2015;79:516-9.

18. Oghan F, Guvey A, Fatih Topuz M, Erdogan O, Guvey H. Effects of vaginal birth versus caesarean section on hearing screening results in a large series from the Aegean region. Int J Audiol. 2020;59(4):310-5.

19. Tabrizi A, Asadi M, Barati B, Shahabi M. Birth by cesarean delivery on newborn screening test: A RETROSPECTIVE STUDY. IJLPR. 2017;7(4):26-9.

20. Farahani F, Hamidi Nahrani M, Seifrabiei MA, Emadi M. The effect of mode of delivery and hospital type on newborn hearing screening results using Otoacoustic emissions: based on screening age. Indian J Otolaryngol Head Neck Surg. 2017;69(1):1-5.

\section{Publisher's Note}

Springer Nature remains neutral with regard to jurisdictional claims in published maps and institutional affiliations.
Ready to submit your research? Choose BMC and benefit from:

- fast, convenient online submission

- thorough peer review by experienced researchers in your field

- rapid publication on acceptance

- support for research data, including large and complex data types

- gold Open Access which fosters wider collaboration and increased citations

- maximum visibility for your research: over $100 \mathrm{M}$ website views per year

At BMC, research is always in progress.

Learn more biomedcentral.com/submissions 